\title{
Putrescine Transport in a Cyanobacterium Synechocystis sp. PCC 6803
}

\author{
Wuttinun Raksajit ${ }^{1,2}$, Pirkko Mäenpää ${ }^{2}$ and Aran Incharoensakdii ${ }^{1, *}$ \\ ${ }^{1}$ Department of Biochemistry, Faculty of Science, Chulalongkorn University, Bangkok 10330, Thailand \\ ${ }^{2}$ Laboratory of Plant Physiology and Molecular Biology, Department of Biology, University of Turku, FIN-20014 Turku, Finland
}

Received February 8 2006, Accepted April 32006

\begin{abstract}
The transport of putrescine into a moderately salt tolerant cyanobacterium Synechocystis sp. PCC 6803 was characterized by measuring the uptake of radioactively-labeled putrescine. Putrescine transport showed saturation kinetics with an apparent $K_{m}$ of $92 \pm 10 \mu \mathrm{M}$ and $V_{\max }$ of $0.33 \pm 0.05 \mathrm{nmol} /$ $\mathrm{min} / \mathrm{mg}$ protein. The transport of putrescine was $\mathrm{pH}$ dependent with highest activity at $\mathrm{pH}$ 7.0. Strong inhibition of putrescine transport was caused by spermine and spermidine whereas only slight inhibition was observed by the addition of various amino acids. These results suggest that the transport system in Synechocystis sp. PCC 6803 is highly specific for polyamines. Putrescine transport is energy-dependent as evidenced by the inhibition by various metabolic inhibitors and ionophores. Slow growth was observed in cells grown under salt stress. Addition of low concentration of putrescine could restore growth almost to the level observed in the absence of salt stress. Upshift of the external osmolality generated by either $\mathrm{NaCl}$ or sorbitol caused an increased putrescine transport with an optimum 2-fold increase at $20 \mathrm{mosmol} / \mathrm{kg}$. The stimulation of putrescine transport mediated by osmotic upshift was abolished in chloramphenicol-treated cells, suggesting possible involvement of an inducible transport system.
\end{abstract}

Keywords: Cyanobacterium, Osmotic activation, Putrescine transport, Synechocystis sp. PCC 6803

\section{Introduction}

Living organisms have evolved strategies for the maintenance of metabolism subject to fluctuations in osmotic strength. The response to hyperosmotic stress can be separated into two main processes. First, the reduction of the water potential after

\footnotetext{
* To whom correspondence should be addressed.

Tel: 662-2185419; Fax: 662-2185418

E-mail: iaran@sc.chula.ac.th
}

hyperosmotic shock causes the cell to lose water and shrink. Consequently, this process is counteracted by an increase in organic solutes entering the cells along chemical gradients (Wood, 1999; Heide et al., 2001). Many organisms that thrive in high salinity use two strategies to acquire high intracellular amounts of compatible solutes: de novo synthesis and/or transport from the surroundings. Salt-loaded cells accumulate compatible solutes, which are low molecular weight compounds that do not interfere with cell metabolism, such as carnitine (Fraser and O'Byrne, 2002), choline (Incharoensakdi and Karnchanatat, 2003), ectoine (Jebbar et al., 1997), glycine betaine (Incharoensakdi and Wutipraditkul, 1999), proline (Dunlap and Csonka, 1985) and polyamines (Flores and Galston, 1984).

Polyamines, represented by putrescine, spermidine and spermine, play important roles in all aspects of cellular processes such as growth, development and biosynthesis (Tabor and Tabor, 1985; Bouchereau et al., 1999; Thomas and Thomas, 2001). Uptake systems specific for polyamines are reported in both prokaryotic and eukaryotic cells (Rinehart and Chen, 1984; Igarashi and Kashiwagi, 1999; Tassoni et al., 2002). The properties of three polyamine uptake systems were characterized by cloning the genes for these systems in Escherichia coli (Igarashi et al., 2001). The first system which is spermidine-preferential consists of PotA, PotB, PotC and PotD proteins whereas the second system which is putrescinespecific consists of PotF, PotG, PotH and PotI proteins. Both systems are classified as ABC [ATP binding cassette]-type transporters. The third system is involved in the excretion of putrescine by a putrescine-ornithine antiporter activity consisting of only the PotE protein. The importance of polyamine uptake by living cells is far from clear, since all organisms have enzymes able to synthesize them and maintain optimum levels for their metabolism. Indeed, most of studies for the uptake of polyamine were carried out in Escherichia coli. There are a few scattered reports on putrescine transport in cyanobacteria. Perhaps the earliest one was the study in Anacystis nidulans where the mechanism of putrescine transport was passive diffusion and ion trapping within the cells (Guarino and Cohen, 1979). 
Synechocystis sp. PCC 6803, which is a moderately salttolerant cyanobacterium, can accumulate glucosylglycerol as an osmoprotective compound by de novo synthesis (Mikkat et al., 1997; Ferjani et al., 2003). Previously, we reported that the effect of long-term salt and osmotic stresses resulted in the increase of the cellular putrescine contents of this cyanobacterium (Jantaro et al., 2003). In the present study, we have investigated putrescine transport in Synechocystis sp. PCC 6803 and found that putrescine transport was energy dependent, specific for polyamines and could be stimulated by moderate osmotic upshift.

\section{Materials and Methods}

Organism and culture conditions. Axenic cells of Synechocystis sp. PCC 6803 were grown photoautotrophically in BG-11 medium at $30^{\circ} \mathrm{C}$ under continuous illumination (warm white fluorescent tubes) of $50 \mu \mathrm{E} / \mathrm{m}^{2} / \mathrm{s}$. The cultivation was performed in cottonplugged 250-ml conical flasks on a rotatory shaker at $160 \mathrm{rpm}$. The growth rate was monitored by measuring the optical density of the culture at $730 \mathrm{~nm}$ with a Spectronic ${ }^{\circledR}$ Genesys ${ }^{\mathrm{TM}} 2$ spectrophotometer.

Transport assays. Cells at late log phase were harvested by centrifugation $\left(8,000 \times g, 10 \mathrm{~min}, 4^{\circ} \mathrm{C}\right)$, washed twice with $50 \mathrm{mM}$ $N$-2-hydroxyethylpiperazine- $N$ '-2-ethanesulfonic acid(Hepes)-KOH buffer $\mathrm{pH} 7.6$ containing $0.4 \%$ glucose and suspended in the same buffer to yield a protein concentration of $0.1 \mathrm{mg}$ cell protein $/ \mathrm{ml}$. The cell suspension $(95 \mu \mathrm{l})$ was preincubated at $37^{\circ} \mathrm{C}$ for $5 \mathrm{~min}$. The uptake experiment was initiated by the addition of $5 \mu \mathrm{l}$ [methylene- ${ }^{14} \mathrm{C}$ ] putrescine (Radiochemical Centre) with a specific activity of $2 \mathrm{mCi} / \mathrm{mmol}$ at a final concentration of $50 \mu \mathrm{M}$. After incubation, the cells were rapidly collected on membrane filters (cellulose acetate, $0.45 \mu \mathrm{m}$ pore size; Millipore Corp.). The filters were washed twice with $1 \mathrm{ml}$ of cold buffer containing $1 \mathrm{mM}$ putrescine to remove the adsorbed [methylene- ${ }^{14} \mathrm{C}$ ] putrescine. The amount of amine adsorbed to the cell surface and the filter was less than $0.1 \%$ of the added amine under these experimental conditions. The radioactivity on the filter was determined with a liquid scintillation counter. Initial putrescine uptake rates were determined from the linear increase of uptake and are expressed as nanomoles of putrescine taken up per minute per milligram protein. Cellular protein was determined by the method of Bradford (1976) using bovine serum albumin as a standard. Cells were lysed by the addition of the Bradford reagent. After centrifugation, the supernatant was measured for optical density at $595 \mathrm{~nm}$. The osmolality of the uptake assay medium was measured with a Wescor vapor pressure osmometer model 5520. For the assay of inhibition by substrate analogs, cells were added to a mixture of labeled substrate and 20fold excess of unlabeled analogs. In inhibitory assays, cells were preincubated with the inhibitor for $30 \mathrm{~min}$ at $37^{\circ} \mathrm{C}$ before the addition of [methylene- ${ }^{14} \mathrm{C}$ ] putrescine.

\section{Results}

Protection against growth inhibition by putrescine. Growth of Synechocystis cells in the medium containing $550 \mathrm{mM}$

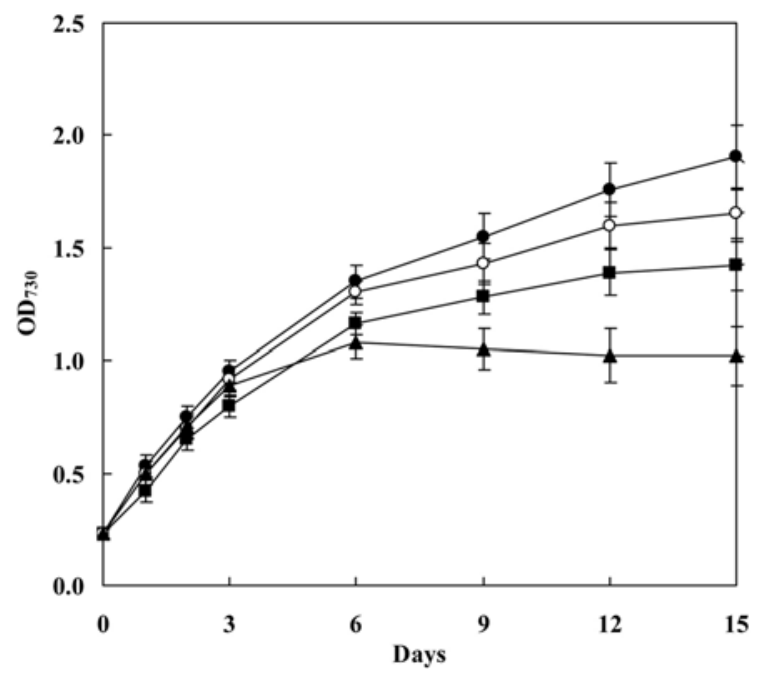

Fig. 1. Growth promoting effect of putrescine on salt-stressed Synechocystis sp. PCC 6803. Cells were grown under normal condition ( ), salt stress condition by the addition of $550 \mathrm{mM}$ $\mathrm{NaCl}(\square), 550 \mathrm{mM} \mathrm{NaCl}$ plus $0.5 \mathrm{mM}$ putrescine $(\bigcirc), 550 \mathrm{mM}$ $\mathrm{NaCl}$ plus $1.0 \mathrm{mM}$ putrescine $(\boldsymbol{\Delta})$. The data are means from three independent experiments with vertical bars representing standard errors of the means, $n=3$.

$\mathrm{NaCl}$ was not as rapid as that in the absence of $\mathrm{NaCl}$ (Fig. 1). Addition of $0.5 \mathrm{mM}$ putrescine could alleviate the effect of salt stress with apparently normal growth up to 6 days. The addition of $1 \mathrm{mM}$ putrescine caused similar growth pattern to that of $0.5 \mathrm{mM}$ putrescine during the first 3 days. Slower growth occurred after 3 days with the apparent cessation of growth observed after 6 days.

Kinetics of putrescine uptake. Incubation of Synechocystis cells with increasing concentration of putrescine up to 500 $\mu \mathrm{M}$ resulted in a saturable initial uptake rate (Fig. 2). A Lineweaver-Burk transformation of the data yielded a straight line typical of Michaelis-Menten kinetics. The apparent affinity constant $\left(K_{m}\right)$ value of $92 \pm 10 \mu \mathrm{M}$ and the maximal velocity $\left(V_{\max }\right)$ value of $0.33 \pm 0.05 \mathrm{nmol} / \mathrm{min} / \mathrm{mg}$ protein were obtained.

Effect of external pH on putrescine uptake. Since putrescine carries a net positive charge, we therefore further tested whether the changes in external $\mathrm{pH}$ could affect its uptake. Among the three $\mathrm{pH}$ values tested, highest uptake occurred at neutral $\mathrm{pH}$ of 7.0 (Fig. 3). Alkaline condition yielded a higher rate of putrescine uptake than acidic condition. The initial rates of putrescine uptake in $100 \mathrm{mM}$ Tris-maleate or Tris$\mathrm{HCl}$ buffer at $\mathrm{pH} 5.5,7.0$, and 8.2 were estimated to be 0.024 $\pm 0.002,0.167 \pm 0.004$, and $0.080 \pm 0.004 \mathrm{nmol} / \mathrm{min} / \mathrm{mg}$ protein, respectively.

Specificity of putrescine uptake. The specificity of putrescine uptake in intact cells was studied by addition of various amine 


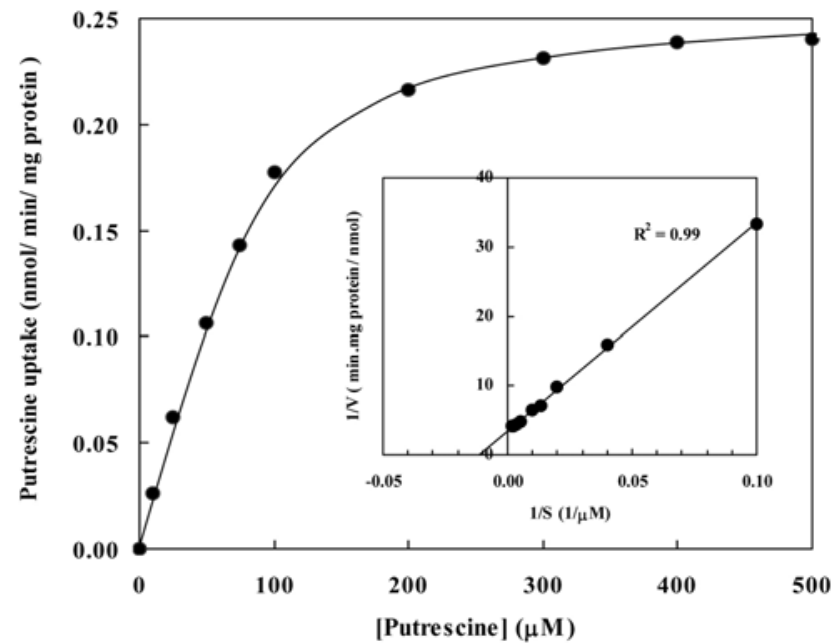

Fig. 2. Kinetics of putrescine uptak by Synechocystis sp. PCC 6803 incubated with $0-500 \mu \mathrm{M}$ putrescine. Initial rates were determined with $1 \mathrm{~min}$ incubation time. Inset represents a Lineweaver-Burk transformation of the data. The line drawn is that derived from regression analysis of the data and the points shown are typical of this result from triplicate experiments.

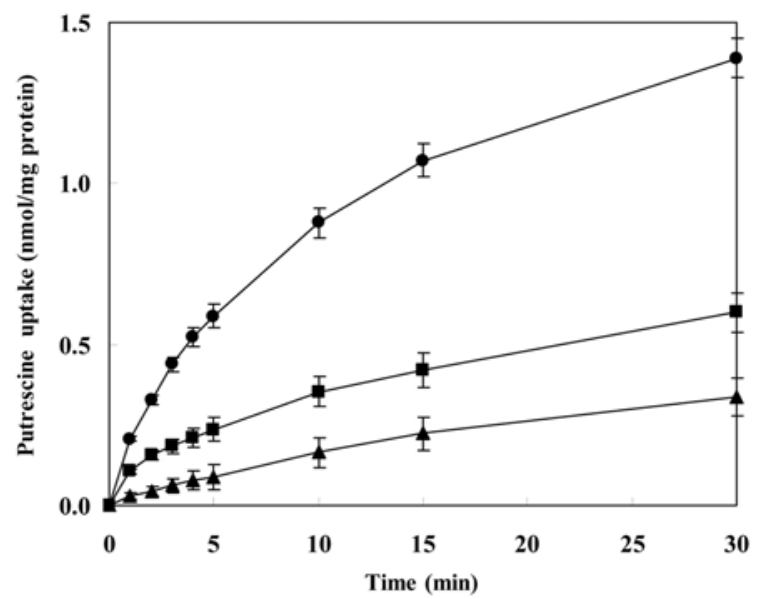

Fig. 3. Dependence of putrescine uptake on external pH. Putrescine uptake assay was done with the modification using $100 \mathrm{mM}$ Tris-maleate for $\mathrm{pH} 5.5(\boldsymbol{\Delta})$ and $100 \mathrm{mM}$ Tris- $\mathrm{HCl}$ for $\mathrm{pH} 7.0$ (O) and $\mathrm{pH} 8.2(\boldsymbol{\square})$. The data are means from three independent experiments with vertical bars representing standard errors of the means, $\mathrm{n}=3$.

analogs into the assay medium and following the rate of uptake. As shown in Table 1, agmatine, a putrescine precursor, had no effect on putrescine uptake. Slight inhibition of putrescine uptake occurred in the presence of alanine, glycine, glutamic acid, and serine. In contrast, spermidine and spermine, which are structurally similar to putrescine but with additional amino groups, showed 40 and $60 \%$ inhibition, respectively.

Inhibition of putrescine uptake by metabolic inhibitors. To determine whether putrescine uptake was energy-dependent, the effects of some inhibitors on the uptake activity were
Table 1. Effect of putrescine analogs on the putrescine uptake of Synechocystis sp. PCC $6803^{a}$

\begin{tabular}{lcc}
\hline Analog compound & Concentration & $\begin{array}{c}\text { Putrescine uptake } \\
(\%)\end{array}$ \\
\hline None & & $100 \pm 2$ \\
Agmatine & $1 \mathrm{mM}$ & $98 \pm 2$ \\
Alanine & $1 \mathrm{mM}$ & $91 \pm 4$ \\
Glycine & $1 \mathrm{mM}$ & $87 \pm 3$ \\
Glutamic acid & $1 \mathrm{mM}$ & $85 \pm 5$ \\
Serine & $1 \mathrm{mM}$ & $84 \pm 3$ \\
Spermidine & $1 \mathrm{mM}$ & $60 \pm 5$ \\
Spermine & $1 \mathrm{mM}$ & $40 \pm 6$ \\
\hline
\end{tabular}

${ }^{a}$ Cells were incubated in the mixture containing $1 \mathrm{mM}$ unlabeled analog and $50 \mu \mathrm{M}$ [Methylene- ${ }^{14} \mathrm{C}$ ] putrescine. Initial rates were determined with $1 \mathrm{~min}$ incubation time. The data shown are the means of three independent experiments representing the percent uptake rate relative to the control rate which was $0.12 \mathrm{nmol} / \mathrm{min} /$ mg protein.

Table 2. Effect of metabolic inhibitors on the putrescine uptake of Synechocystis sp. PCC $6803^{a}$

\begin{tabular}{lcc}
\hline \multicolumn{1}{c}{ Inhibitor } & Concentration & $\begin{array}{c}\text { Putrescine uptake } \\
(\%)\end{array}$ \\
\hline None & & $100 \pm 2$ \\
$N$-Ethylmaleimide & $1 \mathrm{mM}$ & $38 \pm 5$ \\
$p$-Chloromercurisulfonic acid & $1 \mathrm{mM}$ & $20 \pm 5$ \\
Sodium arsenate & $1 \mathrm{mM}$ & $13 \pm 2$ \\
Sodium fluoride & $1 \mathrm{mM}$ & $26 \pm 2$ \\
Potassium cyanide & $1 \mathrm{mM}$ & $39 \pm 7$ \\
Gramicidin D & $10 \mu \mathrm{M}$ & $42 \pm 5$ \\
2,4-Dinitrophenol & $1 \mathrm{mM}$ & $36 \pm 6$ \\
$N, N$-Dicyclohexylcarbodiimide & $80 \mu \mathrm{M}$ & $26 \pm 5$ \\
Valinomycin & $10 \mu \mathrm{M}$ & $9 \pm 3$ \\
Amiloride & $50 \mu \mathrm{M}$ & $11 \pm 4$ \\
\hline
\end{tabular}

${ }^{a}$ Cells were preincubated with inhibitors for $30 \mathrm{~min}$ before the addition of $50 \mu \mathrm{M}$ [methylene- ${ }^{14} \mathrm{C}$ ] putrescine to initiate the uptake with $1 \mathrm{~min}$ incubation as described in Materials and Methods. The data shown are the means of three independent experiments representing the percent uptake rate relative to the control rate which was $0.12 \mathrm{nmol} / \mathrm{min} / \mathrm{mg}$ protein.

studied. Results summarized in Table 2 show that $N$ ethylmaleimide and $p$-chloromercurisulfonic acid, which modify the protein structures, were effective inhibitors of putrescine uptake. The inhibitors for ATP formation, sodium arsenate and sodium fluoride also reduced the uptake activity suggesting the requirement of ATP for putrescine uptake. Interference of electron transport by potassium cyanide resulted in effective inhibition of putrescine uptake. Transport uncouplers such as gramicidin D and dinitrophenol, which dissipate proton motive force, could significantly inhibit putrescine uptake to a similar extent by about $60-65 \% . N, N^{\prime}$ 


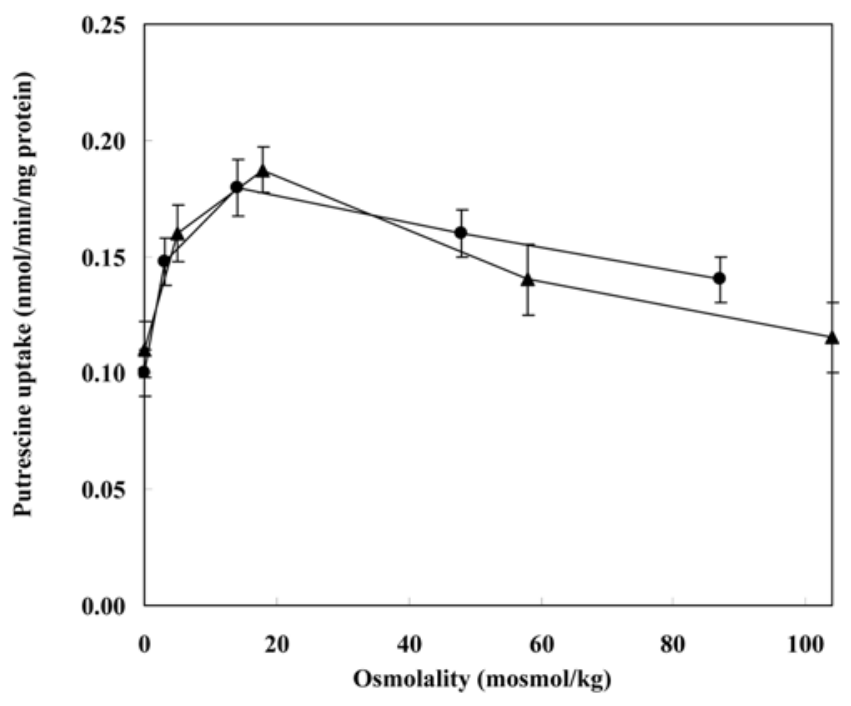

Fig. 4. Effect of external osmolality on putrescine uptake by Synechocystis sp. PCC 6803. Initial uptake rates (1 min incubation) were determined in the presence of increasing osmolality generated by $\mathrm{NaCl}(\boldsymbol{O})$ or sorbitol $(\boldsymbol{\Delta})$. The data are means from three independent experiments with vertical bars representing standard errors of the means, $n=3$.

dicyclohexylcarbodiimide, an ATPase inhibitor causing a reduction in $\mathrm{pH}$ gradient, also effectively inhibited putrescine uptake. Valinomycin, an ionophore collapsing the electrical potential with a reduction in $\psi$, strongly inhibited putrescine uptake. Similarly strong inhibition of putrescine uptake was also observed with amiloride, an inhibitor of $\mathrm{Na}^{+} / \mathrm{H}^{+}$exchanger. All these results collectively indicate that the proton motive force with the contribution of both $\mathrm{pH}$ and $\psi$ (electrical or membrane potential), plays an important role in putrescine transport in Synechocystis cells.

Stimulation of putrescine uptake by osmotic upshift. When testing the effect of osmotic upshift on putrescine uptake, increasing osmolality generated by either $\mathrm{NaCl}$ or sorbitol up to $20 \mathrm{mosmol} / \mathrm{kg}$ caused about 2-fold increase of putrescine uptake compared to the control (Fig. 4). When the osmolality was higher than $20 \mathrm{mosmol} / \mathrm{kg}$ the extent of the stimulation of the uptake was reduced. Moreover, the osmotic upshift higher than $100 \mathrm{mosmol} / \mathrm{kg}$ caused a progressive decline in putrescine uptake (data not shown). It is noteworthy that the uptake of putrescine responded to changes in osmolality with similar pattern regardless of the source generating the osmotic upshift.

Induction of putrescine uptake. Since $\mathrm{NaCl}$-imposed osmotic upshift led to an increase of initial putrescine uptake rate, we investigated whether protein synthesis was involved in the stimulation of putrescine uptake. Pretreatment of cells in the presence of $50 \mathrm{mM} \mathrm{NaCl}$ with chloramphenicol dramatically lowered putrescine uptake rate, i.e. it was decreased to $50 \%$ of that without chloramphenicol pretreatment (Table 3). Cells
Table 3. Effect of chloramphenicol on putrescine uptake of Synechocystis sp. PCC $6803^{a}$

\begin{tabular}{lcc}
\hline \multicolumn{1}{c}{ Condition } & Concentration & $\begin{array}{c}\text { Putrescine uptake } \\
(\%)\end{array}$ \\
\hline Control & & $100 \pm 2$ \\
$\mathrm{NaCl}$ & $50 \mathrm{mM}$ & $142 \pm 3$ \\
$\mathrm{Chloramphenicol}$ & $100 \mu \mathrm{g} / \mathrm{ml}$ & $63 \pm 5$ \\
$\mathrm{NaCl}+$ Chloramphenicol & $50 \mathrm{mM}, 100 \mu \mathrm{g} / \mathrm{ml}$ & $74 \pm 4$ \\
\hline
\end{tabular}

${ }^{a}$ Cells with or without $\mathrm{NaCl}$ were preincubated with chloramphenicol for $30 \mathrm{~min}$ before the addition of $50 \mu \mathrm{M}$ [methylene${ }^{14} \mathrm{C}$ ] putrescine to initiate the uptake with $1 \mathrm{~min}$ incubation as described in Materials and Methods. The data shown are the means of three independent experiments. One hundred percent represents the uptake rate of $0.12 \mathrm{nmol} / \mathrm{min} / \mathrm{mg}$ protein.

pretreated with chloramphenicol in the absence of $\mathrm{NaCl}$ also showed considerable reduction in the rate of putrescine uptake suggesting the involvement of protein synthesis in the uptake process.

\section{Discussion}

Here we have described the existence of a transport system for putrescine in Synechocystis sp. PCC 6803. In a previous study, we demonstrated that Synechocystis cells were able to accumulate polyamines after exposure to long-term osmotic stresses (Jantaro et al., 2003). However, the synthesis of polyamines requires an investment of organic carbon and metabolic energy. It is likely that the portion of cell carbon and energy diverted for polyamine synthesis is at least partially responsible for the observed reduction in the growth rate of cells under osmotic stress. Therefore, the ability to accumulate polyamines via the uptake from the growth medium may be advantageous in terms of the adaptive response to high salinity environment. The data in Fig. 1 indicated that exogenous putrescine could be transported into Synechocystis cells and could act as growth promoter in the presence of high salt concentration. These results seem to suggest the role of putrescine as a compatible solute in this cyanobacterium. Nevertheless, the protective role by putrescine against inhibition of growth under hyperosmotic stress was not as efficient as that by glucosylglycerol, suggesting that putrescine per se is not an osmoprotectant (Ferjani et al., 2003; Mikkat et al., 1997). Indeed, we previously showed that the levels of putrescine accumulated in Synechocystis cells after salt and osmotic stress treatments were not sufficient to account for any osmotic importance (Jantaro et al., 2003). Furthermore, high concentration of intracellular putrescine is detrimental to the growth of cells since the oxidation of polyamines can generate toxic compounds such as acrolein (Sakata et al., 2003). It is worth mentioning here that the addition of exogenous putrescine higher than $1.0 \mathrm{mM}$ was 
inhibitory to the growth of Synechocystis cells. Similar results were reported for Chlamydomonas reinhardtii where cytotoxic effects were observed when exogenous putrescine was higher than $1.5 \mathrm{mM}$ (Theiss et al., 2004). The results in Fig. 1 clearly showed that the growth of Synechocystis cells was inhibited after 6 days in the presence of $1 \mathrm{mM}$ putrescine. This could be ascribed to the toxic effects caused by the accumulation of intracellular putrescine. Previously, it has been shown in Anacystis nidulans that exposure of cells to $150 \mu \mathrm{M}$ putrescine resulted in cell death within $3 \mathrm{~h}$ concomitant with high intracellular putrescine concentration of $100 \mathrm{mM}$ (Guarino and Cohen, 1979).

The putrescine transport system in Synechocystis sp. PCC 6803 was saturable displaying typical Michaelis-Menten type kinetics (Fig. 2). Synechocystis cells exhibited a low affinity $\left(K_{m} 92 \mu \mathrm{M}\right)$ for putrescine transport, which is in contrast to a rather high affinity for $E$. coli with the $K_{m}$ value of $1.4 \mu \mathrm{M}$ (Kashiwaki et al., 1986). Low affinity for putrescine transport indicated the slow uptake of putrescine by Synechocystis cells. This was corroborated by the observations that rather long period of exposure to putrescine was required for growth inhibition and growth stimulation to manifest in the presence of 1.0 and $0.5 \mathrm{mM}$ putrescine, respectively (Fig. 1). The transport system for putrescine in Synechocystis sp. PCC 6803 is an active transport. Putrescine transport is highly inhibited by various energy generation inhibitors (Table 2) suggesting the requirement of energy for the transport system. The coupling mechanism between $\mathrm{Na}^{+}$electrochemical gradient and transport systems has been extensively studied. Previously, we have shown that a halotolerant cyanobacterium Aphanothece halophytica contains $\mathrm{Na}^{+}$-dependent choline and nitrate transport systems (Incharoensakdi and Karnchanatat, 2003; Incharoensakdi and Wangsupa, 2003; Incharoensakdi and Laloknam, 2005). $\mathrm{Na}^{+}$-gradient has been shown to be a major source of energy, coupling with the active transport for polyamine in mouse cells (Rinehart and Chen, 1984). Moreover, the dependency on $\mathrm{Na}^{+}$has been reported for the transport of potassium and bicarbonate into Synechocystis PCC 6803 (Matsuda et al., 2004; Shibata et al., 2002). Although we observed a reduction of putrescine uptake in the presence of amiloride, a $\mathrm{Na}^{+}$-gradient dissipator, it is premature to suggest the involvement of $\mathrm{Na}^{+}$-gradient in the transport of putrescine into Synechocystis cells. The ionophores, valinomycin and 2,4-dinitrophenol and DCCD, an ATPase inhibitor, strongly inhibited the uptake of putrescine, suggesting that the energy required is provided by electron transport in the cytoplasmic membrane through a proton motive force, with the hydrolysis of ATP. Previously, proton motive forcedependent transport of polyamine has been shown in Saccharomyces cerevisiae (Kakinuma et al., 1992) and E. coli (Kashiwaki et al., 1986).

The present study revealed that spermidine and spermine could significantly inhibit the uptake of putrescine in
Synechocystis cells (Table 1) suggesting the same transport system for these three polyamines. Similar observations were reported for the uptake of putrescine by a green alga Chlamydomonas reinhardtii (Theiss et al., 2002). However, in contrast to $C$. reinhardtii the transport of putrescine by Synechocystis cells was influenced by inhibition of protein synthesis (Table 3). On the other hand, no significant inhibition of putrescine transport by various amino acids was observed suggesting a distinctly different transport system for putrescine and amino acids.

Synechocystis cells appeared to possess putrescine transport system with optimal activity around neutral $\mathrm{pH}$ (Fig. 3). This was in agreement with a previous study in a parasitic protozoan, Leishmania mexicana Promastigote (Basselin et al, 2000).

We have shown here that the accumulation of putrescine in Synechocystis sp. PCC 6803 in the presence of low concentration of $\mathrm{NaCl}$ and sorbitol was a result of an osmotic effect rather than an ionic effect. This was based on the results showing that sorbitol with no ionic effect also produced similar pattern of stimulation seen for $\mathrm{NaCl}$ (Fig. 4). It is noted that a marginal level of putrescine uptake could be detected in the absence of osmotic upshift. Without stress this low level of putrescine taken up might serve as nutrient for metabolic function. Increasing the osmolality resulted in the enhancement of the uptake rate since cells require putrescine to better thrive against osmotic upshift. However, at much higher osmolality a decline in putrescine uptake was detected which might be due to less energy available for transport as a consequence of impaired metabolic function. All these results suggested that putrescine transport in Synechocystis was efficient at moderate osmolalities. This was similarly reported in E. coli (Munro et al., 1974). Worth mentioning here is that the slight stimulation of putrescine uptake by both $\mathrm{NaCl}$ and sorbitol could not be ascribed to the osmotic or salt stress effect. The increased uptake might reflect a better physiological state of Synechocystis cells rather than the direct effect on the uptake system. The increase in putrescine uptake would not be related to salt or osmotic acclimation since no parallel increase in the uptake was observed with the increase in the external osmolality.

Results in Table 3 also indicated that protein synthesis is required for the functional putrescine transport since it was significantly inhibited by chloramphenicol. Future work on the characterization of genes as well as the transporters involved in putrescine uptake in Synechocystis sp. PCC 6803 is needed for a better understanding of the putrescine transport system.

Acknowledgments This work was supported by the Thailand Research Fund through the Royal Golden Jubilee Ph.D. Program (PHD/0115/2546) to W. Raksajit and A. Incharoensakdi and partly by the Academy of Finland to P.Mäenpää. 


\section{References}

Basselin, M., Coomb, G. H. and Barrett, M. P. (2000) Putrescine and spermidine transport in Leishmania. Mol. Biochem. Parasitol. 109, 37-46.

Bouchereau, A., Aziz, A., Larher, F. and Martin-Tanguy, J. (1999) Polyamines and environmental challenge: recent development. Plant Sci. Rev. 140, 103-125.

Bradford, M. M. (1976) A rapid and sensitive method for the quantitation of microgram quantities of protein utilizing the principle of protein-dye binding. Anal. Biochem. 72, 248-254.

Dunlap, V. J. and Csonka. L. N. (1985) Osmotic regulation of Lproline transport in Salmonella typhimurium. J. Bacteriol. 163, 296-304.

Ferjani, A., Mustardy, L., Sulpice, R., Marin, K., Suzuki, I., Hagemann, M. and Murata, N. (2003) Glucosylglycerol, a compatible solute, sustains cell division under salt stress. Plant Physiol. 131, 1628-1637.

Flores, H. E. and Galston, A. W. (1984) Osmotic stress-induced polyamine accumulation in cereal leaves. Plant Physiol. 75, 102-109.

Fraser, K. R. and O'Byrne, C. P. (2002) Osmoprotection by carnitine in a Listeria monocytogenes mutant lacking the OpuC transporter: evidence for a low affinity carnitine uptake system. FEMS Microbiol. Lett. 221, 189-194.

Guarino, L. A. and Cohen, S. S. (1979) Uptake and accumulation of putrescine and its lethality in Anacystis nidulans. Proc. Natl. Acad. Sci. USA 76, 3184-3188.

Guarino, L. A. and Cohen, S. S. (1979) Mechanism of toxicity of putrescine in Anacystis nidulans. Proc. Natl. Acad. Sci. USA 76, 3660-3664.

Heide, T., Stuart, M. C. A. and Poolman, B. (2001) On the osmotic signal and osmosensing mechanism of an $\mathrm{ABC}$ transport system for glycine betaine. EMBO J. 20, 7022-7032.

Igarashi, K., Ito, K. and Kashiwagi, K. (2001) Polyamine uptake systems in Escherichia coli. Res. Micromol. 152, 271-278.

Igarashi, K. and Kashiwagi, K. (1999) Polyamine transport in bacteria and yeast. Biochem. J. 344, 633-642.

Incharoensakdi, A. and Karnchanatat, A. (2003) Salt stress enhances choline uptake in the halotolerant cyanobacterium Aphanothece halophytica. Biochim. Biophys. Acta 1621, 102109.

Incharoensakdi, A. and Laloknam, S. (2005) Nitrate uptake in the halotolerant cyanobacterium Aphanothece halophytica is energy-dependent driven by $\Delta \mathrm{pH}$. J. Biochem. Mol. Biol. 38, 467-473.

Incharoensakdi, A. and Wangsupa, J. (2003) Nitrate uptake by the halotolerant cyanobacterium Aphanothece halophytica grown under non-stress and salt-stress conditions. Curr. Microbiol. 47, 255-259.

Incharoensakdi, A. and Wutipraditkul, N. (1999) Accumulation of glycinebetaine and its synthesis from radioactive precursors under salt-stress in the cyanobacterium Aphanothece halophytica. J. Appl. Phycol. 11, 515-523.

Jantaro, S., Mäenpää, P., Mulo, P. and Incharoensakdi, A. (2003) Content and biosynthesis of polyamine in salt and osmotically stressed cells of Synechocystis sp. PCC 6803. FEMS Microbiol.
Lett. 228, 129-135.

Jebbar, M., Blohn, C. and Bremer, E. (1997) Ectoine functions as an osmoprotectant in Bacillus subtilis and is accumulated via the ABC-transport system OpuC. FEMS Microbiol. Lett. 154, 325-330.

Kakinuma, Y., Matsuda, N. and Igarashi, K. (1992) Proton potential-dependent polyamine transport by vacuolar membrane vesicles of Saccharomyces cerevisiae. Biochim. Biophys. Acta 1107, 126-130.

Kashiwaki, K., Kobayashi, H. and Igarashi, K. (1986) Apparently unidirectional polyamine transport by proton motive force in polyamine-deficient Escherichia coli. J. Bacteriol. 165, 972977.

Matsuda, N., Kobayashi, H., Kotoh, H., Ogawa, T., Futatsugi, L., Nakamura, T., Bakker, E. P. and Uozumi, N. (2004) $\mathrm{Na}^{+}-$ dependent $\mathrm{K}^{+}$uptake Ktr system from the cyanobacterium Synechocystis sp. PCC 6803 and its role in the early phase of cell adaptation to hyperosmotic shock. J. Biol. Chem. 279, 54952-54962.

Mikkat, S., Effmert, U. and Hagemann, M. (1997) Uptake and use of the osmoprotective compounds trehalose, glucosylglycerol, and sucrose by the cyanobacterium Synechocystis sp. PCC 6803. Arch. Microbiol. 167, 112-118.

Munro, G. F., Bell, C. A. and Linderman, M. (1974) Multiple transport components for putrescine in Escherichia coli. J. Bacteriol. 118, 952-963.

Rinehart, C. A., Jr. and Chen, K. Y. (1984) Characterization of polyamine transport system in mouse neuroblastoma cells. $J$. Biol. Chem. 259, 4750-4756.

Sakata, K., Kashiwaki, K., Sharmin, S., Ueda, S. and Igarashi, K. (2003) Acrolein produced from polyamines as one of the uraemic toxins. Biochem. Soc. Trans. 31, 371-374.

Shibata, M., Katoh, H., Sonoda, M., Ohkawa, H., Shimoyama, M., Fukuzawa, H., Kaplan, A. and Ogawa, T. (2002) Gene essential to sodium-dependent bicarbonate transport in cyanobacteria, function and phylogenetic analysis. J. Biol. Chem. 277, 1865818664.

Tabor, C. W. and Tabor, H. (1985) Polyamines in microorganisms. Microbiol. Rev. 49, 81-89.

Tassoni, A., Napier, R. M., Franceschetti, M., Venis, M. A. and Bagni, N. (2002) Spermidine-binding protein. Purification and expression analysis in maize. Plant Physiol. 128, 1303-1312.

Theiss, C., Bohley, P., Bisswanger, H. and Voigt, J. (2004) Uptake of polyamines by the unicellular green alga Chlamydomonas reinhardtii and their effect on ornithine decarboxylase activity. J. Plant Physiol. 161, 3-14.

Theiss, C., Bohley, P. and Voigt, J. (2002) Regulation by polyamines of ornithine decarboxylase activity and cell division in the unicellular green alga Chlamydomonas reinhardtii. Plant Physiol. 128, 1470-1479.

Thomas, T. and Thomas, T. J. (2001) Polyamine in cell growth and cell death: molecular mechanisms and therapeutic applications. Cell Mol. Life. Sci. 58, 244-258.

Wood, J. M. (1999) Osmosensing by bacteria: signals and membrane-base sensors. Microbiol. Mol. Biol. Rev. 63, 230262. 